International Journal of Applied Linguistics \& English Literature

ISSN 2200-3592 (Print), ISSN 2200-3452 (Online)

Vol. 1 No. 1; May 2012

\title{
The Effect of Explicit Instruction of Discourse Markers on the Quality of Oral Output
}

\author{
Forough Rahimi \\ Department of Foreign Languages, Shiraz Branch, Islamic Azad University, Shiraz, Iran \\ Email: rahimi.forough@yahoo.com \\ Mohammad Javad Riasati (Corresponding Author) \\ Department of Foreign Languages, Shiraz Branch, Islamic Azad University, Shiraz, Iran \\ Email: mjriasati2002@yahoo.com
}

Received: 02-05- 2012

Accepted: 26-05- 2012

Published: 31-05- 2012

doi:10.7575/ijalel.v.1n.1p.70

URL: http://dx.doi.org/10.7575/ijalel.v.1n.1p.70

\begin{abstract}
The present study was an attempt to investigate the effect of explicit vs. implicit instruction of discourse markers (DMs hereafter) on learners' oral production. To this end, 40 Iranian adult EFL learners (including both males and females) with the age range of 23 to 30 years of age were randomly selected. The sample was randomly divided into two equal groups with 20 members. The control group attending the speaking course received no explicit instruction on DMs, while participants in the experimental group attending the same course, received an explicit treatment on DMs. The experimental group received five sessions of explicit instruction on DMs, consuming 20 minutes of the class time. The data required for the study was collected through semi-structure interview with the participants of the study who spoke on similar topics. Results indicate that the participants in the control group who were exposed to implicit way of teaching discourse markers did not show to use discourse markers frequently. In contrast, the learners in the experimental group who received explicit instruction on discourse markers proved that they used discourse markers frequently in their speech. The final conclusion is that explicit teaching of discourse markers to learners in the experimental group was useful.
\end{abstract}

Keywords: Discourse markers, explicit instruction, oral output

\section{Introduction}

One of the important items for having a fluent use of English is using discourse markers which are a group of cohesive devices that cause the cohesion and smoothness of language. The omission of discourse markers in one's speech may cause his speech to seem dogmatic, impolite, boring, awkward to talk to, etc. As can be seen in native speakers' oral discourse, plenty of various types of discourse markers with different roles are used. In other words, it is quite common for native speakers of every language to apply discourse markers (DMs) in their daily speech and that is why their speech seems quite spontaneous and smooth. As a matter of fact, discourse markers have the role of smoothing spontaneous interaction between speakers and also facilitating comprehension of the hearers. Thus, if L2 learners want to have a more natural and native-like speech, they should adopt DMs and apply them properly in their speech (Fuller, 2003).

Several terms such as discourse marker (Schiffrin 1987), pragmatic marker (Fraser 1996), discourse particle (Schourup 1985), pragmatic particle (Östman 1981), pragmatic expression (Erman 1987), and connectives (Blakemore 1987) are coined and used by some researchers to name the linguistic items that are used as connectors of sentences in discourse. However, the term "Discourse markers" is the most common one employed by most researchers who work on English discourse. In spite of the argument on an appropriate term which can best describe these types of connectors, there is no doubt that DMs play a salient role in the organization of native speaker discourse. Schiffrin (1987) describes DMs as "sequentially dependent elements which bracket units of talk." DMs can facilitate listener comprehension and help smooth spontaneous interaction between speakers through different roles. For example, you know is often used to show the importance of the information conveyed 
International Journal of Applied Linguistics \& English Literature

ISSN 2200-3592 (Print), ISSN 2200-3452 (Online)

Vol. 1 No. 1; May 2012

by the speaker, oh may be used to mark a speaker's receipt of new information, and $o k$ may serve as moving towards closure of speech.

Considering the common use of discourse markers in everyday spoken discourse of native speakers and the important role that DMs play in the coherence and naturalness of speech, it can be concluded that they should be included in EFL classrooms as well. However, based on the previous research such as the one done by Shen Ying (1998) on DMs, reported that DMs are not included in the EFL curricula seriously in spite of the significant role they play in spoken discourse. As De Klerk (2005) mentions, it might be because of "their lack of clear semantic denotation and syntactic role, which makes formal or explicit commentary on their use fairly difficult". Moreover, if an L2 speaker does not apply any DMs, native speakers cannot distinguish any grammatical errors. Hence, since DMs are not explicitly taught in classrooms and L2 speakers can speak grammatically without the employment of discourse markers, these cohesive devices are often invisible for L2 speakers who learn the language in a formal classroom setting. Generally speaking there is a lack of instruction on the use of DMs in formal language classrooms. Besides, the use of DMs is important in native discourse. Studies done on discourse markers so far have suggested that if an L2 speaker is more acculturated to the L2 culture or wants to sound more like a native speaker, he or she may pick up how "things are said" and adopt those "conventional expressions" (i.e. DMs) by the native speakers in the community (de Klerk, 2005; Hellermann and Vergun, 2007). Sankoff et al. (1997) also mention that the use of DMs is an ideal indicator of the extent to which an L2 speaker desires to be integrated into the local community because DMs are often not part of the traditional classroom curriculum and L2 speakers generally acquire these expressions through contact with native speakers. In other words, it is assumed that if an L2 speaker has more contact with the native speakers or desires to be assimilated in the their community, he or she will employ more use of discourse markers in comparison with those who do not.

1.2 Significance of the Study

Regarding that it has been proved that DMs give a well-articulated organizational structure to speech, this study provides the researchers with a clear idea about how Iranian adult EFL learners might benefit to learn more about the importance and application of DMs in their speech. Research on the differences between English discourse produced by a native and non-native speaker (Tyler, 1992) has indicated that native speakers' discourse contains a number of discourse structuring devices that make their speech more comprehensible to their listeners. However, a lack of discourse cues in non-native discourse creates communication problems for native listeners. Moreover, most studies done on DMs in Iran deal with the two skills listening and reading. On the other hand, little research has been done on speaking.

\subsection{Statement of the Problem}

One of the important indices of second/foreign language learners' communicative competence is the ability to form a coherent discourse and maintain discourse cohesion (McCarthy, 1993). Thus, if language learners want to develop connected and well-formed speech, they must develop the ability to use a range of cohesive devices, including discourse markers, in order to organize their oral discourse in a cohesive and smooth manner.

However, it is observed that EFL learners often have various problems in organizing their sentences into a coherent unified whole (Shen Ying, 1998). This issue might be the result of the fact that each language has its own unique system of conveying meaning through oral discourse and since language learners try to transfer their L1 system into the L2 system, they have problems in managing their speech in a smooth and natural way.

On the other hand, the lack of instruction on the appropriate use of DMs in EFL formal language classrooms is often observed and as a result, EFL learners who are mostly far from native speaker contexts and their language learning opportunities are restricted to class hours suffer from this lack of instruction (Shen Ying, 1998).

Therefore, there is a need to deeply explore and distinguish EFL learners' oral discourse to examine the way they try to convey meaning in English through the use of cohesive devices and also distinguish their problems. Then, through the instruction of these discourse markers, teachers can help them to get a better understanding of discourse markers and the way they are used to have a cohesive text in English.

1.4 Purpose of the study

In order to help foreign language learners to develop their communicative competence and find out their problems in the complex process of interlanguage, English instructors need to distinguish learners' ability to maintain discourse cohesion. Hence, this study, aimed at investigating Iranian adult learners' use of a group of cohesive devices i.e. discourse markers in their English oral discourse and exploring if there is any erroneous use, underuse, or overuse of these cohesive devices. It is also aimed to explore the effect of explicit instruction of discourse markers on learners' oral production. Moreover, the present study wants to determine the most frequent DMs used by learners in speaking and comparing them with the DMs which native speakers of English use in their daily 


\section{파망 \\ International Journal of Applied Linguistics \& English Literature \\ ISSN 2200-3592 (Print), ISSN 2200-3452 (Online)}

Vol. 1 No. 1; May 2012

speaking to observe the similarities and differences of them. Based on the purpose of the study, the research questions are as follows:

1. Do Iranian adult EFL learners who receive explicit teaching of discourse markers outperform those who

receive implicit teaching of discourse markers in speaking?

2. Do Iranian adult EFL learners have any underuse of discourse markers in their speaking?

1.5 Null Hypotheses

In order to answer the above questions, the following null hypotheses were formed:

H0-1. There is no difference between the speaking output of the Iranian adult EFL learners who receive explicit DM teaching and the Iranian adult EFL learners who receive implicit DM teaching.

H0-2. There is no underuse of discourse markers in Iranian adult EFL learners' oral production.

\section{Review of Literature}

\subsection{Overview}

Discourse markers (DMs), i.e. expressions like well, but, oh, and you know are linguistic items that function in discourses of various styles or registers. Fraser (1998: 301) calls discourse marker analysis "a growth market in linguistics." Since the late 1980's discourse markers have been studied in a variety of languages and examined in a variety of genres and interactive contexts, though many scholars do not agree on how to define them, even what to call them. Redeker (1991: 1168) calls them discourse operators and defines them as "a word or phrase, for instance, a conjunction, adverbial, comment clause, interjection that is uttered with the primary function of bringing to listener's attention a particular kind of the upcoming utterance with the immediate discourse context." Schiffrin who provides "an operational definition" defines DMs at a more theoretical level as "members of a functional class of verbal and nonverbal devices which provide contextual coordinates for ongoing talk" (1987: 41).

Discourse markers play crucial roles in interactions (Carter and McCarthy 2006), and they have a high frequency of occurrence in spoken discourse. So far, extensive bodies of literature exist on discourse markers (Clark and Fox Tree 2002; Fraser 1990, 1996, 1999; Jucker and Ziv 1998; Schiffrin 1987, 1994; Schourup 1985; Fox Tree and Schrock 2002). However, scholars have no agreement regarding their classifications and functions. This disagreement has partly led to using multifarious terms by different scholars such as discourse marker (Schiffrin 2003), discourse particle (Gupta 2006; Schourup 1985) and pragmatic particle (Östman 1981; Wouk 1998). Also, Fung and Carter (2007:410) have noted that 'relatively limited research has been undertaken on the range and variety of DMs used in spoken English by second or foreign language speakers'. However, in spite of this disagreement, there are numerous DMs which can be easily spotted in conversations. They are expressions like $u h$, um, yeah, and you know.

Discourse markers are defined by Schiffrin $(1987$, p.31) as "sequentially dependent elements which bracket units of talk" and they often help to make interactions coherent by bringing together the different aspects of discourse in a meaningful way. According to Akande (2008, p.81), DMs are "peripheral to the syntax of the sentence or the clause they relate to since they can be omitted without causing any damage to the structure of the sentence or clause". This means that DMs can be omitted and such omission does not affect the truth value of the proposition in the sentence or the clause. DMs are performance additions which convey various communicative intentions without which effective communication in spontaneous talks may be impaired (Levelt, 1989). According to Blakemore (2006, p.221), "this concept (i.e. discourse marker) is generally used to refer to syntactically heterogeneous class of expressions which are distinguished by their function in discourse and the kind of meaning they encode." The basic denominator of all these is that DMs are communicative devices through which participants in conversations can negotiate meaning and cooperate with one another. Syntactically, DMs have peripheral roles and can be omitted without affecting the truth values of the propositions in which they occur (Rouchota, 1998).

DMs are most of the time optional since they have no effect on the propositional contents of the utterances in which they occur. This is attested to by fact that the grammaticality of a sentence remains intact even after the DM in it is removed. The constituents of DMs can be a single word, a phrase or a clause (Gupta, 2006).

Brinton (1996) points out that DM has been the most suggested name for "seemingly empty expressions found in oral discourse", however, she proposes the term pragmatic markers, as pragmatic "better captures the range of functions filled by these items". Although Brinton claims the fact that there has been little agreement on the items that can be called pragmatic markers, she compiles an inventory of thirty three markers that have received scholarly attention and suggests a broad number of characteristics typical of these words. Those characteristics

Page $\mid 72$ 


\section{파망 \\ International Journal of Applied Linguistics \& English Literature \\ ISSN 2200-3592 (Print), ISSN 2200-3452 (Online)}

Vol. 1 No. 1; May 2012

were later taken up by Jucker \& Ziv (1998) who reordered them to gain features that relate to the same level of linguistic description: phonological and lexical, syntactic, semantic, functional and sociolinguistic features.

Since 1987, a great deal of attention has been focused on DMs. Three proposals were developed at roughly the same time; Schiffrin (1987), Blakemore (1987) and Fraser (1988). Schiffrin (1987) presents a very detailed analysis of DMs as linguistic expressions; she studies the semantic and grammatical status of these markers, their functions and characteristics. She maintains that DMs as one of the leading figures in the coherence group, contribute to the coherence of the text by establishing coherence relationships between units of talk (Schiffrin, 1987). Schiffrin gives a detailed analysis of twelve DMs in English: and, but, or, so, well, then, now, because, oh, well, youknow, and I mean. She claims that DMs can function on different levels of discourse structure (linguistic or non-linguistic). They can operate on the 'ideational' (informational) structure in the sense that they indicate relations between ideas in discourse or in other words, they mark the organization of ideas in discourse. For example, a DM such as but indicates that what follows it contrasts with what precedes it. They can also operate on the participation framework (discourse exchange and interaction) in the sense that they play a role in controlling the conversational labor between speakers and hearers as is the case with oh and well.

\subsection{Discourse Marker Use in Spoken Language}

With the growing interest in discourse analysis, in the past 15 years or so, an extensive body of pragmatic and linguistic research has been devoted to a functionally related group of expressions mostly referred to as discourse markers, which are also known by a variety of other competing names, such as pragmatic markers, discourse particles or discourse operators. In addition to the indeterminacy of terminology, scholars have no consensus in regard to the other fundamental issues of DMs, such as their definitions, classifications and functions. The controversy is still open to further elaboration (Lee and Jung, 2005).

The status of well, you know, and I mean as DMs in speech is disclosed by Schiffrin's (1987) preliminary study on DMs, which defines DMs as "sequentially dependent elements which bracket unit of talk." Based on the conversational coherence-based functional approach, she examined eleven DMs in depth, among which well, you know and I mean are included.

In addition, researchers such as Fox Tree and Schrock (1999) propose that the presence of DMs such as well and $I$ mean is one of the most salient features of spontaneous talk. Considering that the use of DMs creates a naturalistic conversational effect, many novelists draw on the given trait to distinguish their descriptions of the setting or plot and the characters' dialogue. For instance, Norrick (2001) examines Mark Twain's "The notorious jumping frog of Calaveras county" to illustrate how the use of well lends verisimilitude to the oral narrative technique of a traditional storyteller. The fact that the early work on DMs focused predominantly on conversational items also reflects the close relationship between DMs and orality. All in all, DM use manifests one of the important dimensions of natural spoken discourse. Discourse analysts and language teachers can barely afford to ignore its significance in spoken language.

\subsection{Explicit vs. Implicit Teaching and Learning}

Almost every language teacher will agree that the controversy of the effectiveness of explicit and implicit teaching has been questioned for decades. Some researchers agree that explicit teaching methods are more beneficial for language learners; some researchers agree that implicit teaching methods are more beneficial for learners; and some researchers believe that a combination of the two methods is beneficial for optimal learning (Lee and Jung, 2005).

\subsection{Explicit Learning and Teaching}

Explicit learning is a "conscious awareness and intention" (Brown, 2007, p.291) to learn. In addition, explicit learning involves "input processing to find out whether the input information contains regularities, and if so, to work out the concepts and rules with which these regularities can be captured" (Brown, 2007, p.291). Explicit learning is an active process where students seek out the structure of information that is presented to them.

Explicit teaching involves directing student attention toward a specific learning objective in a highly structured environment. Topics are taught in a logical order directed by the teacher through demonstration, explanation and practice. Explicit teaching also involved modelling thinking patterns. This involves a teacher thinking out loud while working through a "problem" to help students understand how they should think about accomplishing a task. The attention of students is very important since explicit teaching is very teacher-centered. Explicit teaching is closely related to deductive teaching, which means that rules are given before any examples are seen.

The purpose of explicit teaching is:

Page $\mid 73$ 
International Journal of Applied Linguistics \& English Literature

ISSN 2200-3592 (Print), ISSN 2200-3452 (Online)

Vol. 1 No. 1; May 2012

- Introducing a new topic or skill

- Providing guided instruction for understanding rules, skills, and thinking

- Giving students specific instruction through modelling, which allows students develop understanding through practice (Best et al., 2005).

\subsection{Implicit Learning and Teaching}

Implicit learning is "learning without conscious attention or awareness" (Brown, 2007, p.291). In addition, implicit learning occurs "without intention to learn and without awareness of what has been learned" (Brown, 2007, p.292). Implicit learning is a passive process where students are exposed to information, and acquire knowledge of that information simply through that exposure. Some synonyms of implicit learning are: passive, unintentional, inductive, intuitive, automatic, subconscious acquisition, unreflective, behaviorism, mimicry and memory, exposure to language in use.

Implicit teaching involves teaching a certain topic in a suggestive or implied manner; the objective is not plainly expressed. Implicit teaching is closely related to inductive teaching, which means that rules are inferred from examples presented first. It allows for students to create their own schemas for understanding rules instead of memorizing specific rules which enables long-term memory retention.

The purpose of implicit teaching is:

- Introducing new concepts in a student-centered manner

- Giving students instruction with a variety of several examples, without teaching students the actual grammar rules (Burns and Mason, 2002).

\subsection{The Relationship between SLA and Implicit and Explicit Learning and Teaching}

Many studies have been performed to determine which teaching technique is the most effective according to research results, and according to the Second Language Acquisition theory. A study by Robert DeKeyser reveals that "explicit and deductive learning is better than implicit for simple categorical rules" and "Implicit learning is equally good as or ever better than explicit learning for prototypes. In addition, many researchers have found that a combination of implicit and explicit learning may yield the best results. This is because every learner has a different learning preference, so it is necessary to vary one's teaching method to optimally influence students.

\subsection{Research on Discourse Markers}

Discourse markers have been much studied in the last twenty years; and different proposals and approaches have been developed on this subject. Fraser (1999) refers to their problematic and controversial nature. He points out that DMs have been studied by different researchers under different labels. According to Fraser researchers have agreed that DMs are lexical expressions that relate discourse segments, but they have disagreed on how they are defined and what functions they carry.

While much work has been done in studying the acquisition of English morphology, syntax, and phonology by non-native speakers of English, there is a paucity of research on the acquisition of English DMs by English as a Foreign Language (EFL) learners.

Chaudron and Richards (1986) investigated how different categories of discourse markers affect the degree to which foreign students understand university lectures. They classified cues into macro and micro-markers. According to them, macro-markers are cues used to signal the relationship among main segments or to mark the major transition points in discourse (e.g. what I'm going to talk about today...) while micro-markers are cues employed to indicate inter-sentential relations or to function as pause fillers (e.g. and, so and well). The results showed that macro-markers more significantly helped the learners comprehend the lecture; on the other hand, the beneficial effects for micro-markers in this aspect were not found.

Flowerdew and Tauroza (1995) replicate the study with certain remedies against the flaws aforementioned. They convincingly demonstrate that micro-markers facilitate comprehension of L2 oral texts and suggest that practitioners have been too quick in deemphasizing the importance of micro-markers for comprehension. According to Flowerdew and Tauroza (1995), the counterintuitive findings of Chaudron and Richards (1986) basically resulted from methodological drawbacks in the study design. For instance, the researchers used a scripted text instead of authentic lecture materials for the study. As a result, when the spoken micro-markers were inserted into the written text, they appeared artificial and redundant. In addition, the researchers segmented the text into units no longer than 60 to 90 second to allow their subjects time to complete cloze versions of the lecture. The

Page $\mid 74$ 


\section{파망 \\ International Journal of Applied Linguistics \& English Literature \\ ISSN 2200-3592 (Print), ISSN 2200-3452 (Online)}

Vol. 1 No. 1; May 2012

inserted 40-second pauses at such junctures greatly reduced the risk of their subjects suffering information overload and therefore minimized significance of the markers.

Vasilescu et al. (1998) investigated the role of discourse markers in interactive spoken question answering systems. Their study presents a preliminary analysis of the role of some discourse markers and the vocalic hesitation euh in a corpus of spoken human utterances collected with the RITEL system, an open domain and spoken dialog system. The frequency and contextual combination patterns of classical discourse markers and of the vocalic hesitation has been studied. This analysis highlights some specificities in terms of combination patterns of the analyzed items. They reported that the classical discourse markers seem to help initiating larger discursive blocks both at initial and medial positions of the ongoing turns. The vocalic hesitation also stands for marking the user's embarrassments and wish to close the dialog.

Schourup (1999) expresses similar views. He argues that there is disagreement on fundamental issues in the study of DMs. Researchers are unable to agree on the grammatical category of DMs or how to delimit their class or even what types of meaning these markers express.

Anderson, et al. (1999) compare young children's use of DMs affected by social variables such as age, gender and social class differences in three language communities: 18 middle-class, monolingual English-speaking American children aged 4-7, and the same number of middle-class French monolinguals from Lyon, France and Chicano bilingual children who live in a working class community in Southern California. The researchers find that children across language communities are sensitive to the social meanings conveyed by the use of different DMs even by the time they enter school. The data suggest that English-speaking children have acquired a fair degree of sophistication in how to use a variety of DMs to mark status asymmetry across a variety of situations and roles and to manipulate the social situation where the power relationships are not established.

Fraser (1999) pointed out that the study of DMs has turned into a growth industry in the last ten years. Dozens of articles appear yearly focusing on the nature, meaning and function of DMs. Fraser (1999) investigates the past research and concludes that no clear definition has been given of DMs. He mentions an early reference by Levinson (1983) who considers DMs as a class of linguistic expressions worthy of study in its own rights.

Heeman and Allen (2000) studied Speech Repairs, Intonational Phrases and Discourse Markers. This paper presents a statistical language model in which we redefine the speech recognition problem so that it includes the identification of POS tags, discourse markers, speech repairs and intonational phrases. This model is able to identify $72 \%$ of turn-internal intonational boundaries with a precision of $71 \%, 97 \%$ of discourse markers with $96 \%$ precision, and detect and correct $66 \%$ of repairs with $74 \%$ precision.

Macaulay (2002) makes use of computerized transcription of speech to count the frequency of the use of DM you know in extended samples of speech from a stratified population. Two data-sets are collected: interviews recorded in Ayr and a set of same-sex conversations recorded in Glasgow. The implications suggested by this quantitative study include: The use of you know varies among individuals from similar backgrounds. Speakers are more likely to use you know in conversations with an acquaintance than in interviews with a stranger. Women are more likely to use you know than men. Adolescents have not yet developed the use of you know as a characteristic of their discourse style. And the use of you know does not appear to be primarily based on assumptions of shared knowledge.

Fuller (2003) examines the use of the DMs you know, like, oh, well, yeah, and I mean in two speech contexts, i.e., interviews and casual conversations, to determine their role in marking and negotiating speaker roles. The two speech contexts in the study contrast in three main dimensions: speaker roles (asymmetrical vs. symmetrical), relative intimacy of the speakers (relative strangers vs. intimates), and relative formality of the speech event (semi-formal vs. casual). Based on Jucker and Smith's (1998, cited in Fuller, 2003) study, the researcher classifies you know, like, well and I mean as presentation markers, which are predicted to appear less frequently in the conversation context than in the interviews; oh, and yeah are reception markers and are predicted to appear more frequently in the conversation data. However, based on the study findings, Fuller argues that well also has some feature of a reception marker

Jung (2003) involved 80 Korean EFL learners to investigate the role of discourse signaling cues in L2 listening in hopes of answering the questions of whether and how the combination of macro and micro-markers affect L2 listening comprehension. The study demonstrated that the group listening to a lecture with cues recall significantly more high and low-level information when performing summary tasks than the group listening to a lecture without such cues from the lecture.

Page $\mid 75$ 
International Journal of Applied Linguistics \& English Literature

ISSN 2200-3592 (Print), ISSN 2200-3452 (Online)

Vol. 1 No. 1; May 2012

Fung and Carter (2007) studied Discourse Markers use in Native and Learner. Their study examined and compared the production of discourse markers by native speakers and learners of English based on a pedagogic sub-corpus from CANCODE, a corpus of spoken British English, and a corpus of interactive classroom discourse of secondary pupils in Hong Kong. The results indicated that in both groups discourse markers serve as useful interactional manoeuvres to structure and organize speech on interpersonal, referential, structural, and cognitive levels. The Hong Kong learners are found to display a liberal use of referentially functional discourse markers (and, but, because, OK, so, etc.) but a relatively restricted use of other markers (yeah, really, say, sort of, I see, you see, well, right, actually, you know, etc.). Native speakers are found to use discourse markers for a wider variety of pragmatic functions and the study therefore also discusses some possible pedagogical implications involved in preparing learners to become more interactionaly competent speakers.

Jung (2008) studied Discourse Markers in Cross-Cultural Conversation. Results showed that L2 learners need not only the necessary DMs means but also the ability to use those means in a socially effective manner.

Akande (2009) studied Discourse markers in the spontaneous speech of Nigerian university graduates. This study examined the distribution and the use of discourse markers in the conversation of 30 Nigerian university graduates (NUGs) selected from three university towns; namely Ife, Kano and Nsukka. Evidence from a 30 hour recorded interview shows that discourse markers in the spontaneous speech of NUGs have different socio-pragmatic functions such as reparation, clarification and gap filling. It is found out that there is regional variation in the use of discourse markers between the Southwest (or Southeast) and the North. In addition, it is discovered that of the six discourse markers this study focuses on, uh is the most frequent while I mean is the least frequent in the spontaneous speaking of NUGs.

Ramos (2010) performed a comparative study of the DM types in the body section of the research papers of DLSU students. Two English (Basic Research) classes at De La Salle University - Manila, each composed of between forty and forty-three students who were assigned to work in pairs, were selected. Classes were taken from two colleges. From the two research paper classes, thirty papers were collected. The papers were examined on the basis of what DMs types are predominantly used in the Body section of the students' research papers. This study used Hyland and Tse's Taxonomy of Textual and Interpersonal Metadiscourse (2004) and Halliday and Hasan's (1976) concept of cohesion. Results reveal that the students from the College of Engineering who are required to write a descriptive research paper use the logical connectives of addition and contrast more than they use the other types of DMs. On the other hand, the students from the College of Liberal Arts, who are expected to turn in an argumentative research paper, show preference for the logical connectives of addition, contrast and consequence because the development of the ideas in the research paper needs to escalate into a level where they are supposed to present their contentions to the arguments that they are putting forth.

\section{Method}

\subsection{Participants}

The participants were 40 randomly selected Iranian adult EFL learners, including both male and female learners with the age range of 23 to 30 . They were preparing themselves for the speaking module of Academic IELTS through attending speaking courses held in Bahar Language Institute, Shiraz, Iran. All participants had studied English as a foreign language for 5-7 years before registering for this class. This could ensure the researchers that all the participants had received an approximately same level of instruction in English, and hence quite a homogeneous sample population in terms of English language proficiency is chosen. The sample was randomly divided into two equal groups with 20 members. The control group attending the speaking course received no explicit instruction on DMs, while participants in the experimental group attending the same course, received an explicit treatment on DMs.

\subsection{Instrumentation}

Before attending the IELTS preparation courses, all of the Iranian participants of this study had taken an IELTS mock exam and had received a score between 6 and 6.5 to become eligible for participating in the IELTS courses. Hence, they were approximately at the same level of English language proficiency.

On the other hand, regarding the use of discourse markers by the participants before the treatment, to minimize the individual differences and select a homogeneous sample, a pre-test was run. All the candidates had a conversation on a general topic selected by the researchers such as 'the advantages and disadvantages of public transportation' in pairs. This was done through a semi-structured interview by the researchers. Each participant talked about the selected topic for about three minutes. The participants' oral performances were recorded and then

Page | 76 
International Journal of Applied Linguistics \& English Literature

ISSN 2200-3592 (Print), ISSN 2200-3452 (Online)

Vol. 1 No. 1; May 2012

transcribed for the purpose of further analysis and comparison. The experimental group received five sessions of explicit instruction on DMs, consuming 20 minutes of the class time.

At the end of the treatment, again, the candidates had a conversation on different topics in pairs as a post-test to elicit discourse markers from the participants to observe the difference in performance of the two groups, if any, which could be regarded as the effect of the explicit way of teaching DMs.

\subsection{Procedures}

At first, to make the participants homogeneous, a pre-test was used to investigate the frequency and types of discourse markers used by the learners; i.e. they had a conversation on a general topic while their conversations were audio-recorded. Next, the recorded speech of candidates was transcribed for analysing their discourse markers use. The pre-test evaluations were recorded and the frequency of use of DMs used by each participant was calculated.

Then, the 40 selected EFL learners on the basis of the pre-test were assigned to two IELTS speaking preparation classes. The course was held in 12 two hour sessions with 2 weekly meetings. In one of the classes, the teacher worked in 5 sessions on DMs explicitly i.e. he specified 20 minutes of the class hour to the instruction of discourse markers and students did some practice in order to make sure they had understood the application of the discourse markers properly, but in the other one, the class was held as usual with no explicit referring to DMs. It should be noted that the same teacher instructed the second class as well. At the end of the course, the post-test was conducted, audiotaped and transcribed to investigate if any significant difference was observed in the performance of the two groups. Finally, the results of the pre-test and post-test were compared through a t-test and a percentage rate.

\section{Results and Discussion}

This section presents the results and statistical analyses of pre-tests and post-tests taken by both the experimental and the control groups. The obtained results have been summarized in related tables, followed by a discussion on the presented results.

4.1 Results of t-tests of the experimental and control groups pre-tests

Table $4.1 t$-test results for both groups

\begin{tabular}{cccccccc}
\hline Variable & $\mathrm{N}$ & $\mathrm{M}$ & $\mathrm{SD}$ & $\mathrm{t}$ & $\mathrm{df}$ & $\begin{array}{c}\text { Significance } \\
\text { level }\end{array}$ & $\begin{array}{c}\text { Percentage of } \\
\text { DMs }\end{array}$ \\
\hline Experimental & 20 & 28.35 & 3.48 & 0.41 & 38 & 0.68 & $38 \%$ \\
\hline Control & 20 & 27.85 & 4.17 & & & & $34 \%$ \\
\hline
\end{tabular}

As stated earlier, a pre-test was taken by both experimental and control group participants, to observe and compare the students' performances prior to the treatment. As can be seen form the table, there is a slight non-statistically significant difference between the performances of the experimental and control group on the pre-test. The results indicate that the learners were almost at the same level of English language proficiency, before the researchers started to test the effectiveness of the explicit way of teaching DMs on them. This will ensure us that all the participants in both groups were almost similar at the beginning stage, and any change in their performance is due to the effectiveness of the instruction under investigation.

Moreover, the frequency of the use of DMs in both the experimental and control groups' oral productions were calculated. The percentage rates obtained show that Iranian adult EFL learners do not show a considerable degree of using discourse markers in their speech. In other words, the presented data illustrate that there is an underuse of DMs in the learners' oral production. This data will be used as a means of comparison after the results of post-tests are presented, to see if the explicit way of teaching DMs can effectively escalate their degree of use in the learners' oral performances. 
International Journal of Applied Linguistics \& English Literature

ISSN 2200-3592 (Print), ISSN 2200-3452 (Online)

Vol. 1 No. 1; May 2012

4.2 Results of t-tests of the control group's pre-test and post-test

Table $4.2 t$-tests of the control group's pre-test and post-test

\begin{tabular}{ccccccc}
\hline Variable & N & M & SD & t & df & $\begin{array}{c}\text { Significance } \\
\text { level }\end{array}$ \\
\hline Pre-test & 20 & 27.85 & 4.17 & 0.60 & 19 & 0.55 \\
\hline Post-test & 20 & 27.40 & 3.85 & & & \\
\hline
\end{tabular}

As can be seen in the table, there is no statistically significant difference between the performance of the control group in the pre-test and post-test, which can make us conclude that the implicit way of teaching DMs has not been effective (Significance level 0.001). Students do not show a noticeable progress with regard to this instruction. It seems that the implicit instruction on DMs cannot enhance learners' attention and cannot draw their attention to the instruction being taught. So, they will not notice that the teacher is teaching some DMs that are considered to be important for the improvement of oral fluency. As a result, learning is not enhanced. Therefore, we can draw the conclusion that the implicit technique on teaching DMs has not been useful for the development of the learners' oral production.

\subsection{Results of t-tests of the experimental group's pre-test and post-test}

Table $4.3 t$-tests of the experimental group's pre-test and post-test

\begin{tabular}{ccccccc}
\hline Variable & $\mathrm{N}$ & $\mathrm{M}$ & $\mathrm{SD}$ & $\mathrm{t}$ & $\mathrm{df}$ & $\begin{array}{c}\text { Significance } \\
\text { level }\end{array}$ \\
\hline Pre-test & 20 & 28.35 & 3.48 & 6.79 & 19 & 0.0001 \\
\hline Post-test & 20 & 32.10 & 3.87 & & & \\
\hline
\end{tabular}

The analysis of the obtained data indicates a significant difference between the pre-test and post-test of the experimental group at the significance level of 0.0001 . This shows that there is a significant difference in the performance of the experimental group, when they receive the instruction on the DMs explicitly as compared to the case when they receive the instruction implicitly. The data show that when the students are taught explicitly, their use of DMs increases in their speech. The results of the post-test of the participant in the experimental group also show that they have benefited from the explicit instruction on teaching DMs.

4.4 Results of $t$-tests of the experimental and control groups' post-test

Table $4.4 t$-tests of the experimental and control groups' post-test

\begin{tabular}{cccccccc}
\hline Variable & $\mathrm{N}$ & $\mathrm{M}$ & $\mathrm{SD}$ & $\mathrm{t}$ & $\mathrm{df}$ & $\begin{array}{c}\text { Significance } \\
\text { level }\end{array}$ & $\begin{array}{c}\text { Percentage of } \\
\text { DMs }\end{array}$ \\
\hline Experimental & 20 & 32.10 & 3.87 & & & & $69 \%$ \\
\hline Control & 20 & 37.40 & 3.85 & & 3.84 & 0.0001 & $37 \%$ \\
\hline
\end{tabular}

This table shows the results of data analysis and the comparison of the control and the experimental groups post-tests. The results mark a significant difference between the performances of these two groups on the post-test (Significance level 0.005). The participants in the control group that have received the instruction on DMs implicitly do not show a progress in the use of DMs in their speech. The participants in the experimental group, on the other hand, mark a great advance in the post-test. It means that receiving the explicit instruction on DMs, has positively and significantly affected their oral performance. In other words, the participants in the experimental group have outperformed those in the control group, and this indicates the effectiveness of explicit instruction on DMs to Iranian adult EFL learners.

Page | 78 


\section{International Journal of Applied Linguistics \& English Literature}

ISSN 2200-3592 (Print), ISSN 2200-3452 (Online)

\section{Vol. 1 No. 1; May 2012}

A comparison made between the frequency of use of DMs between the participants in the experiment group and those in the control group also marks a difference. The post-test data show that the participants in the experimental group have used DMs more in their speech as compared to the participants in the control group, and as compared to their performance on their own pre-test. The frequency of use of DMs in the speech of the participants in the experimental group is $38 \%$ in the pre-test. But after receiving the explicit technique of teaching DMs, it is increased to $69 \%$. It is concluded that the learners use DMs more often in their speech after they are taught explicitly.

\subsection{Summary}

Table 4.5 summarizes the results of the $t$-tests run to compare the performances of the experimental and control groups when they receive implicit vs. explicit instruction on DMs.

Table 4.5 Summary of $t$-tests results for both groups

\begin{tabular}{|c|c|c|c|c|c|c|c|}
\hline Variable & $\mathrm{N}$ & M & SD & $\mathrm{t}$ & $\mathrm{df}$ & $\begin{array}{c}\text { Significance } \\
\text { level }\end{array}$ & $\begin{array}{c}\text { Percentage of } \\
\text { DMs }\end{array}$ \\
\hline Pre-test E & 20 & 28.35 & 3.48 & & & & $38 \%$ \\
\hline Pre-test C & 20 & 27.85 & 4.17 & 0.41 & 38 & 0.68 & $34 \%$ \\
\hline Post-test E & 20 & 32.10 & 3.87 & 3.84 & 38 & 0.0001 & $69 \%$ \\
\hline $\begin{array}{c}\text { Post-test } \\
\text { C }\end{array}$ & 20 & 37.40 & 3.85 & & & & $37 \%$ \\
\hline
\end{tabular}

The results show that the participants in the experimental group have outperformed the participants in the control group when they have received the explicit instruction on DMs. Therefore, it can be concluded that they have benefited from the explicit instruction on DMs. It is observed that the performance of the participants in the control group has not changed significantly. So, the implicit instruction on DMs has not been effective for the learners to improve their speaking skill. This may lead us to conclude that the explicit instruction on DMs can be more beneficial as compared to implicit instruction.

Moreover, the data show that the learners do not show a great use of DMs in their speech when they receive no instruction, or the implicit instruction, on DMs (38\% for the participants in the experimental group's pre-test, 34\% for the participants in the control group's pre-test, and 37\% for the participants in the control group's post-test). On the contrary, they have used a greater number of DMs in their speech when they are taught DMs directly and explicitly (69\% for the participants in the experimental group's post-test). This increase in the frequency of use of DMs is attributed to the explicit instruction on DMs that the learners have received. This contributes to the development of EFL learners' oral fluency skills.

\section{Conclusions}

In this section, the two research questions raised in the first chapter will be answered one by one.

1. Do Iranian adult EFL learners who receive explicit teaching of discourse markers outperform those who receive implicit teaching of discourse markers in speaking?

The first research question of the study sought if there is any difference between learners' use of discourse markers between those who received explicit instruction and those who were exposed to implicit type of instruction. Results of the study proved that the participants in the experimental group who received explicit instruction on discourse markers made more frequent use of them in their oral production. On the contrary, the learners who were in the control group and received implicit instruction did not use discourse markers frequently in their speech. Put it simply, the participants in the experimental group outperformed those in the control group. This could be attributed to the effect on explicit instruction of discourse markers to language learners. This shows that the explicit teaching of discourse markers to learners could be beneficial to them and increases their performance. Page $\mid 79$ 
International Journal of Applied Linguistics \& English Literature

ISSN 2200-3592 (Print), ISSN 2200-3452 (Online)

Vol. 1 No. 1; May 2012

Trillo (2002) and Muller (2005), too, believe that a general neglect of knowledge of DMs in the foreign language teaching curriculum seems to be unjustifiable. Such being the case, the first null hypothesis of the study, which states that there is no difference between the speaking output of the Iranian adult EFL learners who receive explicit DM teaching and the Iranian adult EFL learners who receive implicit DM teaching, is rejected.

2. Do Iranian adult EFL learners have any underuse of discourse markers in their speaking?

The second research question of the study investigated if Iranian EFL learners use sufficient number of discourse markers in their speaking. The results demonstrate that learners who took part in the study did not use discourse markers frequently in their speech. The results of pre-tests and also the performance of the control group who received no explicit instruction on DMs indicate that the learners do not use DMs very often in their speech. However, the results of the post-test showed that the participants used more discourse markers in their speech. This can be the result of the explicit instruction they were exposed to during the treatment.

To conclude, the second null hypothesis of the study which states that there is no underuse of discourse markers in Iranian adult EFL learners' oral production, is rejected.

\section{Pedagogical Implications}

Several implications can be drawn from the present study:

1. One implication for language teachers is that any kind of explicit instruction can be more useful and productive that the implicit type. As the results of the study proved, the participants in the experimental group who were exposed to explicit instruction on DMs outperformed those in the control group who got implicit instruction on DMs.

2. Another implication for language teachers is that discourse markers had better be taught explicitly rather than implicitly. As findings of the study proved, the language learners who got explicit instruction on discourse markers showed a better performance in comparison with those who were taught implicitly. Moreover, language teachers are recommended to teach language learners discourse markers since it was shown in the study such knowledge would help learners make more use of discourse markers, which will thus lead to a better performance in their speaking skill.

3. Language learners are also advised to make themselves familiar with discourse markers and their applications in their speech. Such knowledge will help them boost their knowledge of discourse markers and hence their oral performance.

\section{References}

Akande. A. T. (2009). Discourse markers in the spontaneous speech of Nigerian university graduates. Lagos Papers in English Studies, 4, 28-37.

Anderson, E. S., Brizuela, M. Dupuy, B. \& Gonnerman, L. (1999). Cross-linguistic evidence for the early acquisition of discourse markers as register variables. Journal of Pragmatics 31, 1339-1351.

Anstey, M. (1998). 'Being explicit about literacy instruction'. The Australian Journal of Language and Literacy. 2, 1, 200-206.

Best, R.M., Rowe, M., Ozuru, Y., \& McNamara, D.S. (2005). Deep-level comprehension of science texts: The role of the read and the test. Lippincott Williams \& Wilkins, 25, 1, 65-83.

Blakemore, D. (2002). Relevance and linguistic meaning: The semantics and pragmatics of discourse markers. Cambridge: Cambridge University

Blass, R. (1990). Relevance relations in discourse. Cambridge: Cambridge University Press.

Brinton, L. (1996). Pragmatic markers in English: Grammaticalization and discourse functions. Berlin/New York: Mouton de Gruyter.

Burns, R.B., \& Mason, D.A. (2002). Class composition and student achievement in elementary schools. American Educational Research Journal, 39(1), 207-233.

Chaudron, C. \& Richards J. (1986). The effect of discourse markers on the comprehension of lectures. Applied Linguistics 7, 113-127.

Feng, L. (2010). Discourse markers in English writing. The Journal of International Social Research, 3, 11, 299-305.

Page | 80 


\section{International Journal of Applied Linguistics \& English Literature}

ISSN 2200-3592 (Print), ISSN 2200-3452 (Online)

Vol. 1 No. 1; May 2012

Flowerdew, J. \& Tauroza, D. (1995). The effects of discourse markers on second language lecture comprehension. Studies in Second Language Acquisition, 17, 435-458.

Fox, J., E. Schrock. (2002). Basic meanings of you know and I mean. Journal of Pragmatics 34, 727-747.

Fraser, B. (1988). Types of English discourse markers. Acta Linguistica Hungarica 38, 1, 19-33.

Fraser, B. (1990). An approach to discourse markers. Journal of Pragmatics 14, 383- 395.

Fuller, J. M. (2003). The influence of speaker role on discourse marker use. Journal of Pragmatics 35, 23-45.

Fung, L and R, Carter. (2007). Discourse markers and spoken English: Native and learner use in pedagogic settings. Language Teaching Research 11, 2, 159-182.

Heeman, P and J, Allen. (2000). Speech repairs, intonational phrases and discourse markers: Modeling speakers' utterances in spoken dialogue. Computational Linguistics, 25, 4. 80-122.

Hussein, M. (2005). Two accounts of discourse markers in English. Journal of Pragmatics, 49, 75-86

Jucker, A., \& Ziv, Y. (1998). Discourse markers: Descriptions and theory. Amsterdam/ Philadelphia: John Benjamins.

Jung, E. H. (2003). The role of discourse signaling cues in second language listening comprehension. The Modern Language Journal, 87, 562-576.

Jung, J. (2008). Discourse markers in cross-cultural conversation. Working Papers in TESOL \& Applied Linguistics, 8, 2, 1-4.

Lee, B. and Jung, C. (2005). Discourse marker teaching in college conversation classrooms: Focus on well, you know, I mean. Cambridge: Cambridge University Press.

Lenk, Uta. (1998): Marking discourse coherence: Functions of discourse markers. Tubingen: Gunter Narr Verlag.

Lewis, Diana M. (2003). "Rhetorical motivations for the emergence of discourse particles, with special reference to English of course". In Ton van der Wouden, Ad Foolen and Piet Van de Craen (eds.) Particles (Belgian Journal of Linguistics vol. 16). Amsterdam: John Benjamins, 79-91.

Macaulay, R. (2002). You know, it depends. Journal of Pragmatics 34, 749-767.

Nadie, A. (2007). The use of discourse markers in three academic lectures. Asian EFL Journal 9(1), 22-38.

Ramos, J. (2010). A comparative study of the discourse marker types in the body section of the research papers of DLSU students. TESOL Journal, 2, 62-73.

Redeker, G. (1990). Ideational and pragmatic markers of discourse structure. Journal of Pragmatics 14(3), $367-81$.

Schiffrin, D. (1986). Discourse markers: Studies in interactional sociolinguistics. Cambridge: Cambridge University Press.

Schiffrin, D. (1987) ). Discourse markers. Cambridge: Cambridge University Press.

Schourup, L. (1999). Discourse markers. Lingua 3(4), 227-265.

Smith, Sara W. \& Andreas H. Jucker (2000). Actually and other markers of an apparent discrepancy between propositional attitudes of conversational partners. In G. Andersen \& T. Fretheim (eds.) Pragmatic Markers and Propositional Attitude. Amsterdam: John Benjamins.

Tateyama, Y., Kasper, G., Mui, L., Tay , H., \& Thananart, O. (1997). Explicit and implicit teaching of pragmatic routines. In L. Bouton (Ed.), Pragmatics and language learning, Vol. 8 (pp. 163-177). Urbana, IL: University of Illinois at Urbana-Champaign University Press.

Vasilescu, I., S, Rosset and M, Decker. (1998). On the role of discourse markers in interactive spoken question answering systems. Journal of Pragmatics, 30, 485-496. 